\title{
Aging and Wealth Inequality in a Neoclassical Growth Model
}

\author{
Guillaume Vandenbroucke
}

In this article, the author uses a version of the neoclassical growth model with overlapping generations of individuals to investigate the effect of aging on wealth inequality. When an economy's population becomes older-that is, when the proportion of individuals 65 years of age and older increasestwo effects are at work: a direct effect from the changing age composition of the population and an indirect, equilibrium effect from the change in asset holdings by owner's age. The main result is that wealth inequality in an aging population may decrease or increase depending on the cause of the aging. An increase in life expectancy tends to increase inequality, whereas a reduction in the population growth rate tends to reduce it. (JEL E1, E2, J1)

Federal Reserve Bank of St. Louis Review, First Quarter 2016, 98(1), pp. 61-80.

\section{BACKGROUND FACTS}

A fraction of wealth inequality is attributable to the age composition of a population because older individuals have had more time to accumulate wealth than younger individuals. Figure 1 illustrates this for selected years using U.S. data from the Survey of Consumer Finances. Young households start with little wealth and accumulate more until they reach 65 to 74 years of age. After that point, they deplete their wealth. There are large (i.e., between fivefold and tenfold) differences in wealth between the old and the young. A question then arises: What effect would a change in the age composition of a population have on wealth distribution?

\subsection{Aging Around the World}

There are substantial demographic differences across countries, as well as demographic transformations within particular countries over time, that motivate studying the effect of demography on economic variables. Figure 2 illustrates this point: It shows the proportion of the population 65 years and older in a selected sample of countries since 1960. In the United States, for example, less than 10 percent of the population was 65 or older in 1960. In 2014,

Guillaume Vandenbroucke is a research officer and economist at the Federal Reserve Bank of St. Louis.

(c) 2016, Federal Reserve Bank of St. Louis. The views expressed in this article are those of the author(s) and do not necessarily reflect the views of the Federal Reserve System, the Board of Governors, or the regional Federal Reserve Banks. Articles may be reprinted, reproduced, published, distributed, displayed, and transmitted in their entirety if copyright notice, author name(s), and full citation are included. Abstracts, synopses, and other derivative works may be made only with prior written permission of the Federal Reserve Bank of St. Louis. 


\section{Figure 1}

\section{Mean Net Worth by Age of Head of Household}

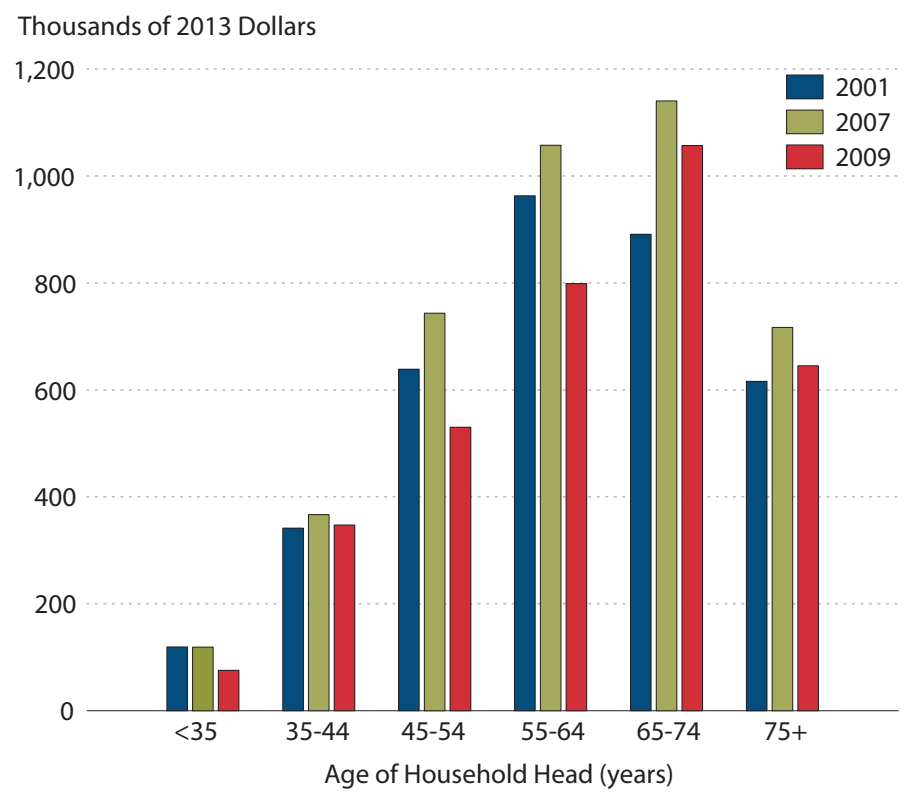

NOTE: The figure shows the net worth by age composition within the U.S. population for the years 2001, 2007, and 2009. SOURCE: Survey of Consumer Finances, 2013 Chartbook.

however, this proportion was almost 15 percent. This is what it means for a population to become older.

Figure 2 reveals that populations in developed countries-such as the United States, Japan, France, and Germany-are noticeably older than those in developing countries such as China or India. In 2014, the proportion of people 65 and older in the latter group of countries was below 10 percent, while in the former group it was 15 percent or higher. Figure 2 also reveals that all populations in the sample became older, albeit at different paces, since 1960. Of particular interest is the Japanese population, the oldest population in the sample (in 2014). Japan experienced the fastest aging process: In 1960, its share of people 65 and older was less than that of the United States, but in 2014 Japan's share exceeded that of the United States. India, the youngest population in the sample, is also remarkable. Even though its share of people 65 and older increased from less than 5 percent in 1960 to 5 percent in 2014, this increase was small relative to that of the older economies in the sample.

\subsection{Measuring Wealth Inequality}

The question in this article can then be phrased as follows: "How does wealth inequality change when the proportion of older people changes?" How does one measure inequality, though? In this article, I use a Gini index. A simple example can help to illustrate how this approach works. Imagine a world populated by young and old people. Suppose there are as 


\section{Figure 2}

\section{Fraction of Population 65 Years of Age or Older}
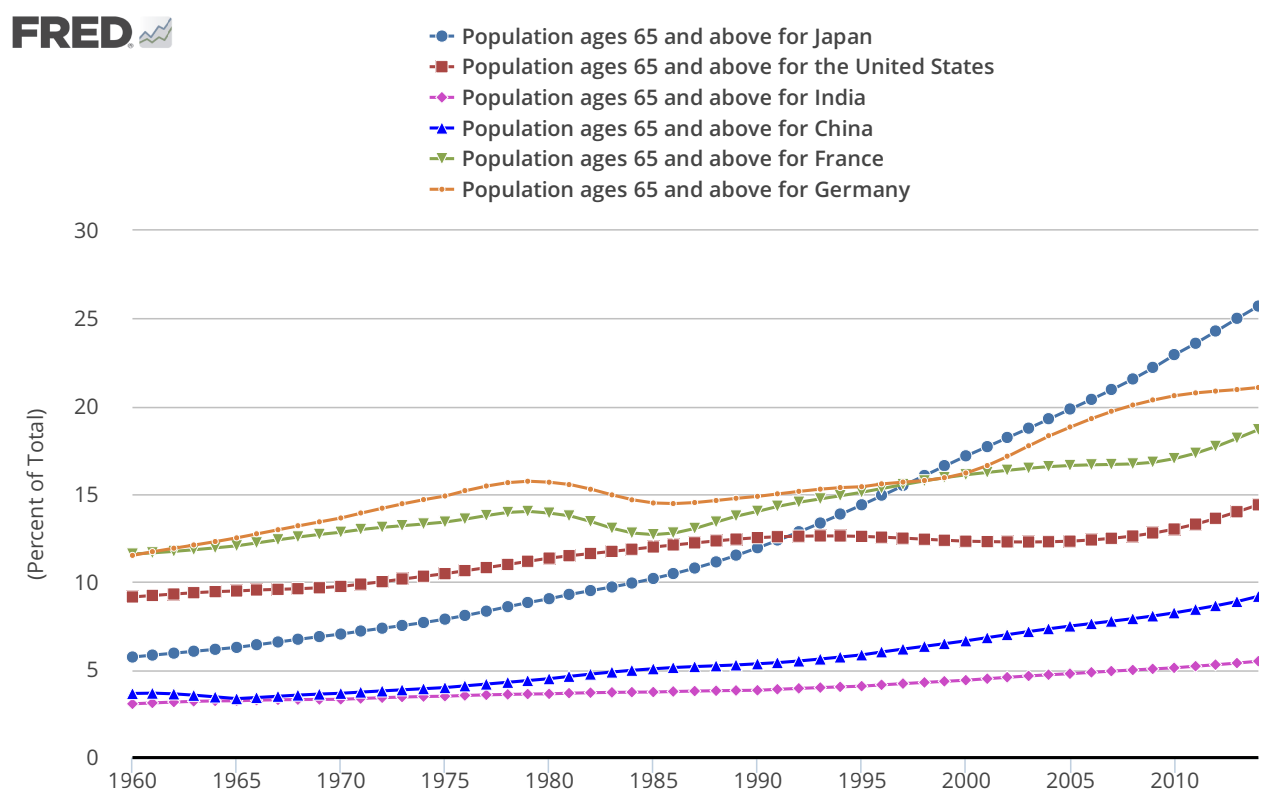

NOTE: The figure shows the proportion of the population 65 years and older in a selected sample of countries since 1960. SOURCE: FRED ${ }^{\oplus}$, Federal Reserve Economic Data, Federal Reserve Bank of St. Louis; https://research.stlouisfed.org/fred2/graph/?g=2pxM.

many young people as old people; the proportion of young (and old) is, therefore, 50 percent. Suppose now that young people hold 50 percent of the total wealth and that older people hold the remaining 50 percent. This world features no inequality: The proportion of the total wealth held by any group of individuals is the same as the proportion this group represents in the total population. Panel A of Figure 3 illustrates this scenario. The horizontal axis measures the cumulative proportions of the population, and the vertical axis measures the cumulative proportions of wealth. The distribution of wealth in the economy is represented by the straight line overlapping the 45-degree line.

Suppose, now, that the young still represent 50 percent of the population but hold only $1 / 3$ of the total wealth (Panel B of Figure 3). The shaded area in this panel-that is, the difference between the actual distribution and the 45-degree line (which represents perfect equality of asset holdings) - is a measure of wealth inequality. Consider a third case: The young still hold $1 / 3$ of the total wealth (as in Panel B) but they now represent $2 / 3$ of the total population (Panel C). Again, the measure of inequality has changed relative to Panels A and B.

The curves represented in Figure 3 are so-called Lorenz curves. The Gini coefficient is calculated as the ratio between the shaded area and the total area under the 45-degree line. Thus, in Panel A the Gini coefficient is 0, illustrating no inequality. In panel B the Gini coefficient is 0.16. In Panel C it is 0.33 . 


\section{Figure 3}

\section{Measurement of Wealth Inequality}
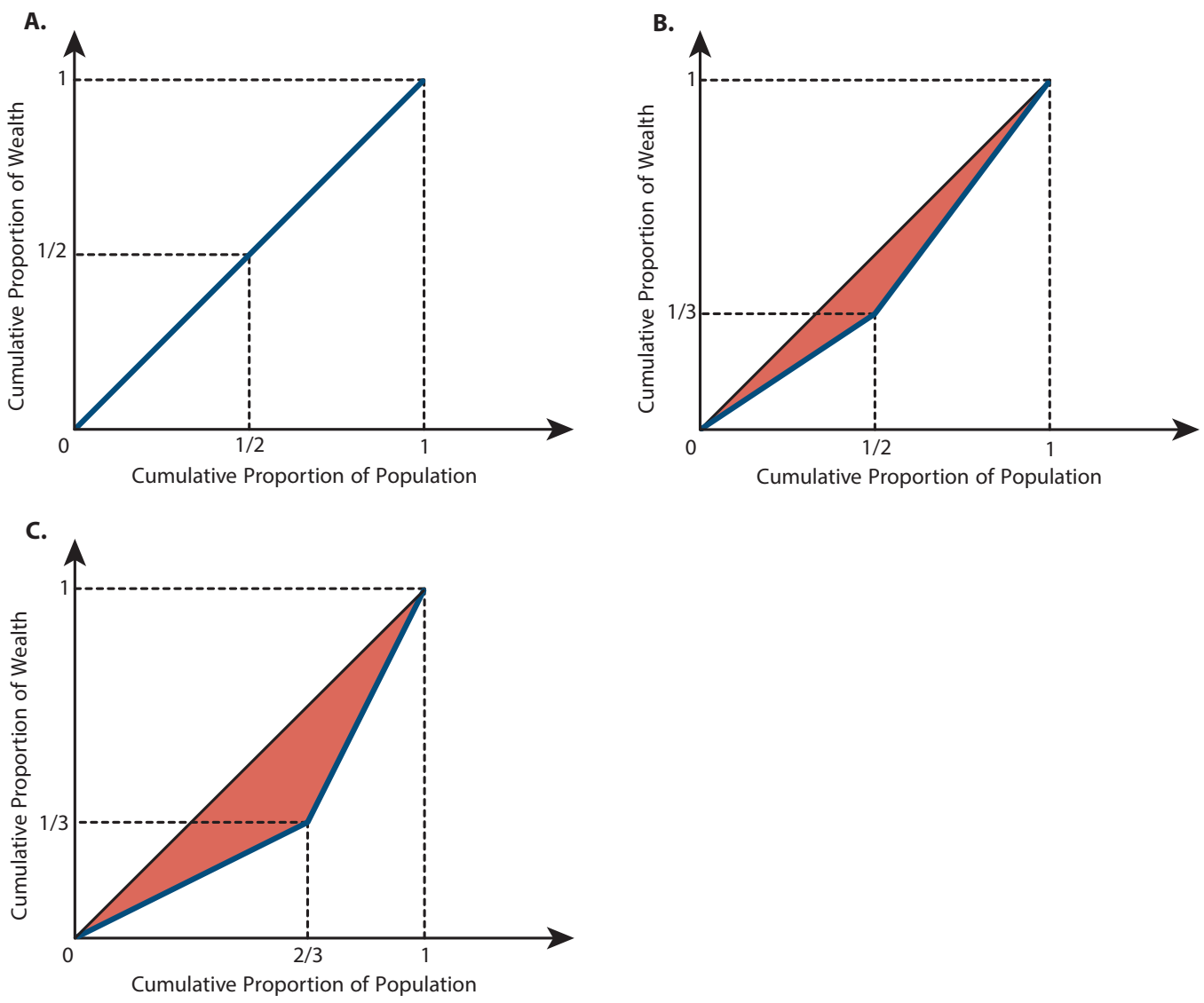

NOTE: In this example, there is no inequality in Panel A. The shaded area in Panels B and C is a measure of inequality.

\subsection{This Article}

It is important to note that in the data, not all variations in wealth are explained by age. Díaz-Giménez, Glover, and Ríos-Rull (2011) discuss measures of wealth inequality and show substantial inequality both within age groups and across age groups. Thus, here I do not attempt to explain overall wealth inequality. Instead, my goal is to discuss a few fundamental mechanisms that relate wealth inequality to demographic changes. In this spirit, I use a deterministic version of the optimal growth model. The model is augmented with a simple demographic structure of overlapping generations, which permits a sensible discussion of demographic changes. I use this model even though it is known that, in its simple version, it does not yield accurate quantitative predictions for the distribution of wealth. This model, however, is the workhorse of macroeconomics and the forces at work in its simpler version are likely to be at work in more sophisticated versions as well. Thus, the question asked here can be qualified 
as follows: "How would a change in a population's age composition affect the distribution of wealth, holding constant all other factors that may also affect the wealth distribution?" A related paper by Chatterjee (1994) also uses a version of the optimal growth model to discuss wealth inequality. His focus, however, is on the transitional dynamics of inequality and abstracts from demographic considerations.

How does the optimal growth model help to analyze the effect of demographic changes on the distribution of wealth? Suppose, for instance, that a world as in Panel C of Figure 3 exists, where the young represent $2 / 3$ of the total population and hold $1 / 3$ of the total wealth. To assess the effect of an aging population, one could compare Panel $\mathrm{C}$ with Panel $\mathrm{B}$, since the only difference between them is the proportion of young people, which decreases from $2 / 3$ in Panel C to 1/3 in Panel B. This approach amounts to using the observed relation between age and asset holdings and combining it with different age compositions of the population to measure the effect of the age composition on wealth inequality. There seems to be no need for a model. This approach may be misleading, however. Young people may no longer hold $1 / 3$ of the total wealth when their proportion in the population changes. One key reason for this is that, as the proportions of the young and the old change, aggregate savings changes as well. The interest rate may increase or decrease, implying different saving behaviors. One needs, therefore, a theory of saving decisions and of the interest rate to reliably analyze the effects of demographic changes. The optimal growth model provides this theory. This point is akin to the well-known Lucas critique (see Lucas, 1976).

\section{THE MODEL}

\subsection{Demography}

The economy is populated by generations of individuals living for $J$ periods, indexed by $j=1, \ldots, J$. The size of the age- $j$ population at time $t$ is denoted by $p_{t}^{j}$. The laws of motion for $p_{t}^{j}$ are

$$
\begin{gathered}
p_{t}^{1}=n p_{t-1}^{1} \\
p_{t}^{j}=p_{t-1}^{j-1} \text { for } j=2, \ldots, J .
\end{gathered}
$$

Equation (1) describes the population growth: Each age-1 individual at time $t$ "gives birth" to $n$ children, who become age- 1 individuals in the next period. Children are economically inactive and birth is not a choice. Equation (2) describes aging: Each individual becomes one year older every year. Thus, the population of individuals of age $j-1$ at time $t-1$ is of age $j$ at time $t$. Let $P_{t}$ denote the total population at date $t$ :

$$
P_{t}=\sum_{j=1}^{J} p_{t}^{j} .
$$




\subsection{Technology and Profit Maximization}

Aggregate output, $Y_{t}$, is produced by a representative firm operating a constant returns to scale aggregate technology:

$$
Y_{t}=K_{t}^{\theta}\left(z_{t} N_{t}\right)^{1-\theta}
$$

where $\theta \in(0,1), z_{t}$ is labor-augmenting productivity, $K_{t}$ is the aggregate stock of capital, and $N_{t}$ is labor demand. Productivity grows at the constant (gross) rate $g: z_{t+1} / z_{t}=g$. Capital depreciates at rate $\delta \in(0,1)$. Note that the assumption of constant returns to scale implies that the number of firms does not matter. That is, the production side of the economy would be strictly identical if there were many small identical firms operating the same constant returns to scale technology.

The objective of the firm is to maximize profit:

$$
\max _{K_{t}, N_{t}} K_{t}^{\theta}\left(z_{t} N_{t}\right)^{1-\theta}-w_{t} N_{t}-\left(r_{t}+\delta\right) K_{t},
$$

where $w_{t}$ is the wage rate and $r_{t}$ is the interest rate prevailing between periods $t-1$ and $t$.

\subsection{Preferences and Individual Optimization}

The preferences of an age- 1 individual at date $t$ are represented by

$$
\sum_{j=1}^{J} \beta^{j-1} \frac{\left(c_{t+j-1}^{j}\right)^{1-\sigma}}{1-\sigma}, \sigma>0,
$$

where $\beta \in(0,1)$ is the subjective discount factor and $c_{t+j-1}^{j}$ is consumption at age $j$ (date $t+j-1$ ). The individual does not value leisure. Thus, labor supply is inelastic and equals 1 each period when the individual works. There is an exogenously given retirement age, $R$. That is, from age $R$ to $J$, the labor supply is zero. Let $a_{t+j-1}^{j}$ denote the assets owned by the individual at the beginning of age $j$ (date $t+j-1$ ). At age 1 the individual is endowed with zero assets. That is, $a_{t}^{1}=0$. The period budget constraint at age $j$ is then

$$
c_{t+j-1}^{j}+a_{t+j}^{j+1}=w_{t+j-1} \mathbb{I}(j<R)+\left(1+r_{t+j-1}\right) a_{t+j-1}^{j},
$$

where $\mathbb{I}(j<R)$ is an indicator function that takes the value 1 whenever $j<R$ and 0 otherwise. The left-hand side of this constraint indicates the expenditures of an age- $j$ individual: consumption and savings. The right-hand side indicates the individual's sources of revenue: labor if he is not retired and revenue from past savings.

\subsection{Equilibrium}

An equilibrium is a sequence of wages and interest rates, $\left\{w_{t}, r_{t}\right\}$, together with sequences of capital stock and labor demand for the firm, $\left\{K_{t}, N_{t}\right\}$, and sequences of consumption and savings for individuals, $\left\{c_{t}^{j}, a_{t+1}^{j+1}\right\}$, such that the following conditions are satisfied: 
(i) Profit maximization: The sequences $\left\{K_{t}, N_{t}\right\}$ solve the optimization problem of the firm at each date $t$ (equation (4)), given the sequence of wages and interest rates, $\left\{w_{t}, r_{t}\right\}$.

(ii) Utility maximization: The sequences $\left\{c_{t}^{j}, a_{t+1}^{j+1}\right\}$ solve the optimization problem of age- 1 individuals at each date $t$; that is, the sequences maximize utility (5) subject to the sequence of budget constraints (6), given the sequence of wages and interest rates, $\left\{w_{t}, r_{t}\right\}$.

(iii) Market clearing:

(a) The labor market clears at each date $t$. That is, the labor demand by the firm, $N_{t}$, equals the labor supply by working individuals: $\sum_{j=1}^{R-1} p_{t}^{j}$. So, the labor market
clearing condition is

$$
N_{t}=\sum_{j=1}^{R-1} p_{t}^{j}
$$

(b) The market for savings clears at each date $t$. That is, the supply of funds by individuals, $\sum_{j=1}^{J} p_{t}^{j} a_{t+1}^{j+1}$, equals the demand for capital for the following period, $K_{t+1}$. So, the savings market clearing condition is

$$
K_{t+1}=\sum_{j=1}^{J} p_{t}^{j} a_{t+1}^{j+1} .
$$

Note that, since age- $J$ individuals do not save, this equation can also be written as $K_{t+1}=\sum_{j=1}^{J-1} p_{t}^{j} a_{t+1}^{j+1}$, and since it must hold at any date $t$, it must hold at $t-1$ : $K_{t}=\sum_{j=1}^{J-1} p_{t-1}^{j} a_{t}^{j+1}$. Finally, using equation (2) and the assumption that individuals are born without assets, $a_{t}^{1}=0$, the savings market clearing condition also reads

$$
K_{t}=\sum_{j=1}^{J} p_{t}^{j} a_{t}^{j}
$$

which means that the aggregate stock of capital is held by individuals at the beginning of period $t$.

(c) The market for goods clears at each date $t$. The demand for goods (that is, the sum of consumption and investment, $\sum_{j=1}^{J} p_{t}^{j} c_{t}^{j}+K_{t+1}-(1-\delta) K_{t}$, equals the supply, $Y_{t}$. So, the goods market clearing condition is

$$
\sum_{j=1}^{J} p_{t}^{j} c_{t}^{j}+K_{t+1}=Y_{t}+(1-\delta) K_{t}
$$




\subsection{Balanced Growth}

The analysis of this economy focuses on its "balanced growth path" — that is, an equilibrium where variables grow at constant (possibly zero) rates. The appendix shows the derivation of the equations characterizing the balanced growth path.

Along the balanced growth path the aggregate stock of capital, $K_{t}$, and aggregate output, $Y_{t}$, grow at the (gross) rate $g n$. The interest rate, $r_{t}$, is constant and the wage rate, $w_{t}$, grows at the (gross) rate $g$. This implies that an individual's labor income grows at rate $g$ over his lifetime. Finally, population, $P_{t}$, grows at the (gross) rate $n$.

For future reference, it is useful to note one result derived in the appendix: The share of age- $j$ individuals in the total population is constant over time and denoted by $\pi^{j} \equiv p_{t}^{j} / P_{t}$, where

$$
\pi^{j}=\frac{1}{n^{j-1} x(n, J)}
$$

and $x(n, J) \equiv \sum_{j=1}^{J} 1 / n^{j-1}$. To understand equation (11), consider the case where $n=1$. The equation implies that the population distribution is uniform and that $\pi^{j}=1 / J$. That is, the proportion of individuals of all ages is the same. This is because age-1 individuals are "born" at the same rate at which age- $J$ individuals "die." When $n$ increases above 1 , age- 1 individuals are born at a faster rate than the rate at which age- $J$ individuals die. This implies that the proportion of young individuals increases and that that of old individuals decreases. This is most transparent when $J=2$ since, in this case, $\pi^{1}=n /(1+n)$, which is increasing in $n$, and $\pi^{2}=1 /(1+n)$, which is decreasing in $n$.

\section{QUANTITATIVE ANALYSIS}

\subsection{Calibration}

Let age 1 in the model correspond to age 18 in the data, and let $J_{\text {bench }}=63$. That is, people live until the equivalent of 80 years of age. Let the retirement age be $R_{\text {bench }}=48$ (that is, 65 years old in the data). Let $\pi^{65+}(n, J)$ denote the proportion of individuals age 65 and older:

$$
\pi^{65+}(n, J)=\sum_{j=48}^{J} \pi^{j}
$$

The benchmark population growth rate, $n_{\text {bench }}$, is set at 1.015 so that $\pi^{65+}\left(n_{\text {bench }}, J_{\text {bench }}\right)=$ 0.17 , which is the proportion of the population age 65 and older in the population of individuals age 18 and older in the U.S. data in 2010. In fact, the U.S. population age 18 and older grew from 209.13 to 234.56 million individuals between 2000 and 2010. This represents an average growth rate of 1.1 percent per year versus 1.5 percent in the model.

The capital share of output $\theta$ is set at a standard value of $\theta=1 / 3$. The growth rate of laboraugmenting technological progress, $g$, is set so that the economy's balanced growth path features 2 percent growth in per capita quantities per year. Hence, $g=1.02$. The investment-to- 


\section{Table 1}

\section{Calibration of the Benchmark Economy}

\begin{tabular}{ll} 
& \multicolumn{1}{c}{ Parameters } \\
\hline Demography & $n_{\text {bench }}=1.105, J_{\text {bench }}=63, R_{\text {bench }}=48$ \\
Preferences & $\sigma=1.0, \beta=0.97$ \\
Technology & $\theta=1 / 3, g=1.02, \delta=0.04$ \\
\hline
\end{tabular}

\section{Figure 4}

\section{Profile of Assets and Population Distribution by Age and Lorenz Curve: Calibrated Economy}

\section{A. Assets by Age}

Assets

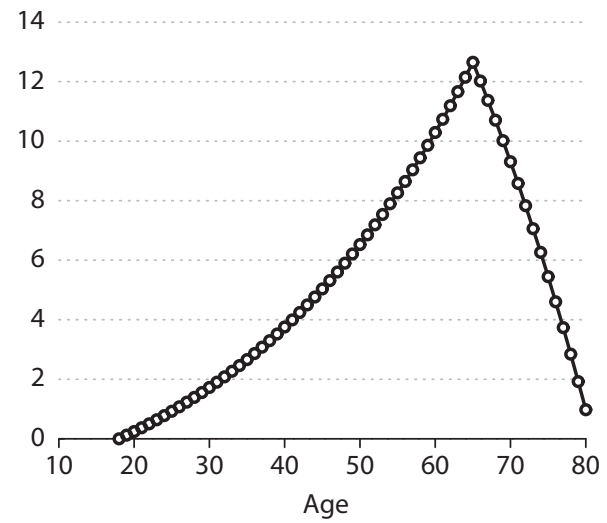

\section{Lorenz Curve}

Cumulative Proportion of Assets

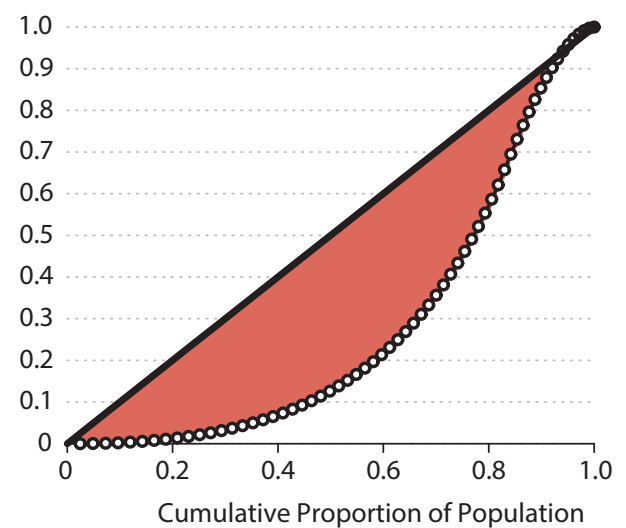

\section{B. Population by Age}

Percent of Total Population

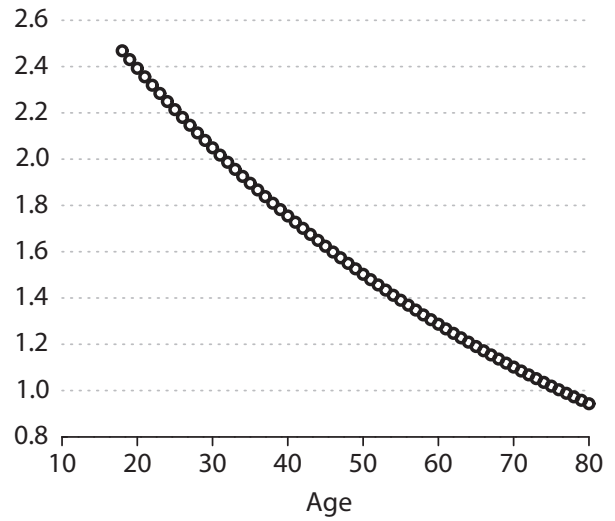

NOTE: The figure shows the balanced growth path distributions of assets and population by age (Panels A and B), as well as the Lorenz curve for assets (Panel C) in the calibrated economy. 
capital ratio is $g n+\delta-1$. Following Cooley and Prescott (1995), I set the rate of depreciation $\delta$ so that the investment-to-capital ratio equals 7.6 percent; this yields $\delta=0.04$. The period utility index is logarithmic: $\sigma=1$. Finally, I set $\beta=0.97$ so that the capital-to-output ratio is 3.3. The equilibrium interest rate implied by this calibration is $r=5$ percent per year. This figure compares with a 4 percent rate of return on U.S. Treasury inflation-protected securities of various maturities (see McGrattan and Prescott, 2001).

Table 1 presents the list of calibrated parameters. Figure 4 shows the profile of assets by age (Panel A), the population distribution by age (Panel B), and the Lorenz curve (Panel C) in the balanced growth path of the calibrated economy. Individuals exhibit a typical behavior for this class of models: They accumulate assets until they retire. Then they live off their savings and deplete their assets. This explains the inverted- $V$ pattern of the asset profile. Note that the asset profile implied by the model matches the qualitative pattern exhibited by the empirical profiles in Figure 1. The calibrated economy features a Gini coefficient of 0.45 for the distribution of assets.

\subsection{Changes in the Age Composition of the Population}

The effect of a change in the age composition of the population depends on the cause of this change. In the context of the model developed here, there are two exogenous variables driving the age composition: the population growth rate, $n$, and life expectancy, J. This transpires in equation (11).

3.2.1 The Effect of Population Growth. I consider different values for the population growth rate, $n$, holding life expectancy, $J$, constant. For each value of $n$, I compute a balanced growth path. I choose the values of $n$ to exemplify a specific point-namely, that wealth inequality is not monotonic in the age composition of the population.

Panel A of Figure 5 shows the Gini coefficient plotted against the share of individuals age 65 and older implied by the different values of $n$. The main message is that, as the proportion of individuals age 65 and older increases because of a decreased population growth rate, wealth inequality measured by the Gini coefficient decreases, reaches a minimum, and then increases. In particular, Panel A of Figure 5 shows that wealth inequality is the same when the share of individuals age 65 and older is 17 percent or 60 percent.

Table 2 reports statistics from the model's balanced growth path for three values of $n$ : $\left(n_{\text {bench }}, n_{1}, n_{2}\right)=(1.015,0.984,0.952)$. Start with the benchmark economy and contemplate what happens when $n$ is lowered from 1.015 to 0.984 . The share of individuals age 65 and older increases from 17 percent to 37 percent. Panel B of Figure 5 shows this by comparing the distribution of the $n_{\text {bench }}$ economy (black circles) with that of the $n_{1}$ economy (red squares). The lower proportion of young individuals relative to the $n_{\text {bench }}$ economy implies a higher stock of capital per worker. There are two reasons for this. First, there is a direct effect: There are fewer workers since the demography changed. Second, there is an equilibrium effect: There is more capital in the economy to finance the consumption of the larger number of retirees. Such a higher stock of capital per worker explains the decrease in the interest rate from 5.0 percent to 4.0 percent. At this rate future consumption is more expensive, so individuals 


\section{Figure 5}

\section{Effect of a Change in Population Growth Rate}

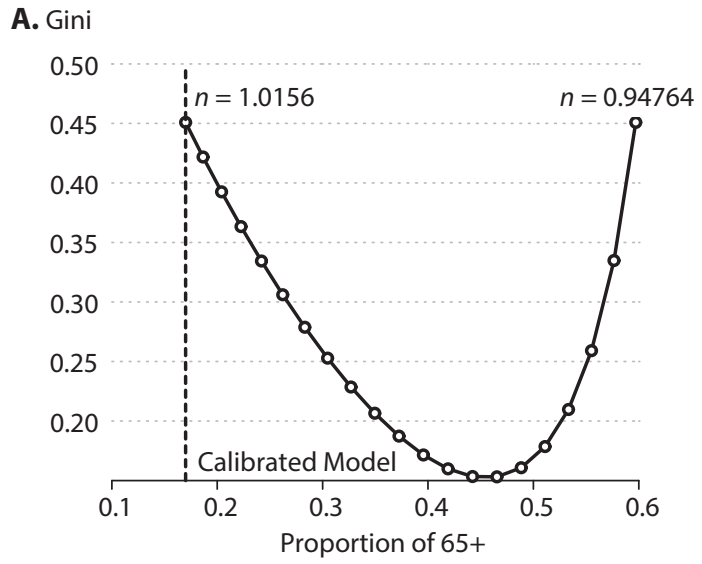

C. Assets

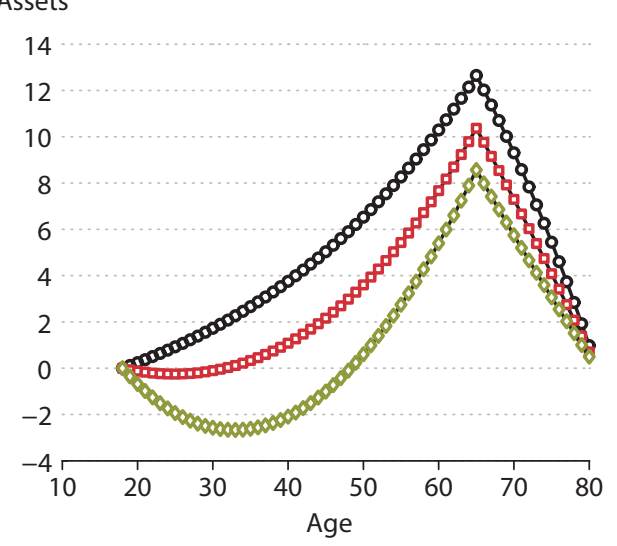

B. Proportion of Total Population

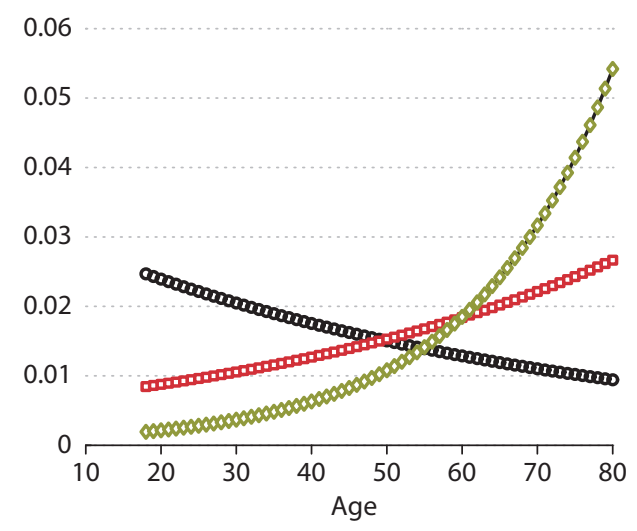

$\multimap n=1.015$, Gini $=0.45$

$\rightarrow-n=0.981$, Gini $=0.18$

$\rightarrow-n=0.947$, Gini $=0.45$

NOTE: Panel A plots the Gini coefficient in the steady state as a function of the proportion of individuals age 65 and older. Panel B plots the population distribution by age in three selected balanced growth paths. Panel C plots the asset profiles by age in the same three steady states.

\section{Table 2}

Comparative Statistics Across Balanced Growth Paths: Selected $n$

\begin{tabular}{|c|c|c|c|c|}
\hline $\begin{array}{l}\text { Population } \\
\text { growth rate, } n\end{array}$ & $\begin{array}{l}\text { Proportion } \\
\text { of } 65+, \pi^{65+}\end{array}$ & $\begin{array}{c}\text { Capital } \\
\text { per worker, } k\end{array}$ & Interest rate, $r$ & $\begin{array}{c}\text { Gini } \\
\text { coefficient }\end{array}$ \\
\hline$n_{\text {bench }}=1.015$ & 0.17 & 5.52 & 0.050 & 0.45 \\
\hline$n_{1}=0.981$ & 0.37 & 6.45 & 0.041 & 0.18 \\
\hline$n_{2}=0.947$ & 0.60 & 7.76 & 0.031 & 0.45 \\
\hline
\end{tabular}




\section{Vandenbroucke}

accumulate fewer assets over their lifetimes. Panel C of Figure 5 shows that the asset profile of the $n_{\text {bench }}$ economy is above that of the $n_{1}$ economy. ${ }^{1}$

There are, therefore, two factors affecting the change in wealth inequality between the $n_{\text {bench }}$ economy and the $n_{1}$ economy: a change in the distribution of assets by age and a change in the age composition of the population. In Figure 3, the former is represented, albeit in a simplified way, by the change from Panel A to Panel B; I refer to this as the "economic effect." The latter is represented by the change from Panel B to Panel C; I refer to this as the "demographic effect." I follow a procedure used by Greenwood and Seshadri (2002) and Greenwood and Vandenbroucke (2008) to assess the contribution of these two factors. Define the Gini coefficient as a function $G(a, \pi)$, where $a$ and $\pi$ represent vectors of assets and the population share by age, respectively: $a \equiv\left(a^{j}\right)_{j=1}^{J}$ and $\pi \equiv\left(\pi^{j}\right)_{j=1}^{J}$. The change in the Gini coefficient from $G(a, \pi)$ to $G\left(a^{\prime}, \pi^{\prime}\right)$ satisfies

$$
\begin{aligned}
G\left(a^{\prime}, \pi^{\prime}\right)-G(a, \pi) & =\underbrace{\left[G\left(a^{\prime}, \pi^{\prime}\right)-G\left(a, \pi^{\prime}\right)\right]}_{X_{1}}+\underbrace{\left[G\left(a, \pi^{\prime}\right)-G(a, \pi)\right]}_{X_{2}} . \\
& =\underbrace{\left[G\left(a^{\prime}, \pi^{\prime}\right)-G\left(a^{\prime}, \pi\right)\right]}_{X_{3}}+\underbrace{\left[G\left(a^{\prime}, \pi\right)-G(a, \pi)\right]}_{X_{4}} .
\end{aligned}
$$

Note that the terms $X_{1}$ and $X_{4}$ measure the effect of a change in $a$, holding $\pi$ constant: the economic effect. The difference between $X_{1}$ and $X_{4}$ is the value at which $\pi$ is held: the final value, $\pi^{\prime}$, for $X_{1}$ and the initial value, $\pi$, for $X_{4}$. Similarly, the terms $X_{2}$ and $X_{3}$ measure the contribution of a change in $\pi$, holding $a$ constant at either its initial or final value: the demographic effect. Summing the two rows of this system and dividing by 2 yields

$$
\begin{aligned}
G\left(a^{\prime}, \pi^{\prime}\right)-G(a, \pi)= & \underbrace{\left[G\left(a^{\prime}, \pi^{\prime}\right)\right]-G\left(a, \pi^{\prime}\right)+G\left(a^{\prime}, \pi\right)-G(a, \pi) / 2}_{\text {Effect of } a} \\
& \underbrace{\left[G\left(a^{\prime}, \pi^{\prime}\right)\right]-G\left(a^{\prime}, \pi\right)+G\left(a, \pi^{\prime}\right)-G(a, \pi) / 2}_{\text {Effect of } \pi}
\end{aligned}
$$

where the economic effect, for example, is the average of the effects of a change in a holding $\pi$ constant at its initial and final values.

Table 3 shows the results of this decomposition as $n$ changes from $n_{\text {bench }}$ to $n_{1}$ and then from $n_{1}$ to $n_{2}$. Consider the change from $n_{\text {bench }}$ to $n_{1}$ first. The Gini coefficient decreases by 26 percentage points. Table 3 shows that the economic effect tends to raise the Gini coefficient by 14 percentage points, while the demographic effect lowers it by 40 percentage points. The net effect equals the total effect by construction. Why does the economic effect, the change in the asset profile by age, contribute to more inequality? This occurs because the reduction in asset holdings is not uniform across age groups as the interest rate decreases. Figure 6 shows that, from one balanced growth path to the next, individuals with the most asset holdings reduce their holdings relatively less than others. The 20 -year-olds, for instance, reduce their asset holdings by 250 percent between the $n_{\text {bench }}$ economy and the $n_{1}$ economy, while the 60 year-olds reduce theirs by less than 50 percent. Thus, given an age distribution for the population, a reduction in the interest rate results in an increased concentration of wealth, which 


\section{Table 3}

\section{Decomposition of the Change in the Gini Coefficient with Population Growth Rate Changes}

\begin{tabular}{lccr} 
& $\boldsymbol{n}_{\text {bench }}$ & $\boldsymbol{n}_{1}$ & $\boldsymbol{n}_{2}$ \\
\hline Gini & 0.45 & 0.21 & 0.45 \\
Total effect & & -0.26 & +0.26 \\
Effect of $a$ & & +0.14 & +0.73 \\
Effect of $\pi$ & & -0.40 & -0.47 \\
\hline
\end{tabular}

\section{Figure 6}

\section{Change in Assets by Age from the $n_{\text {bench }}$ to the $n_{1}$ Economy}

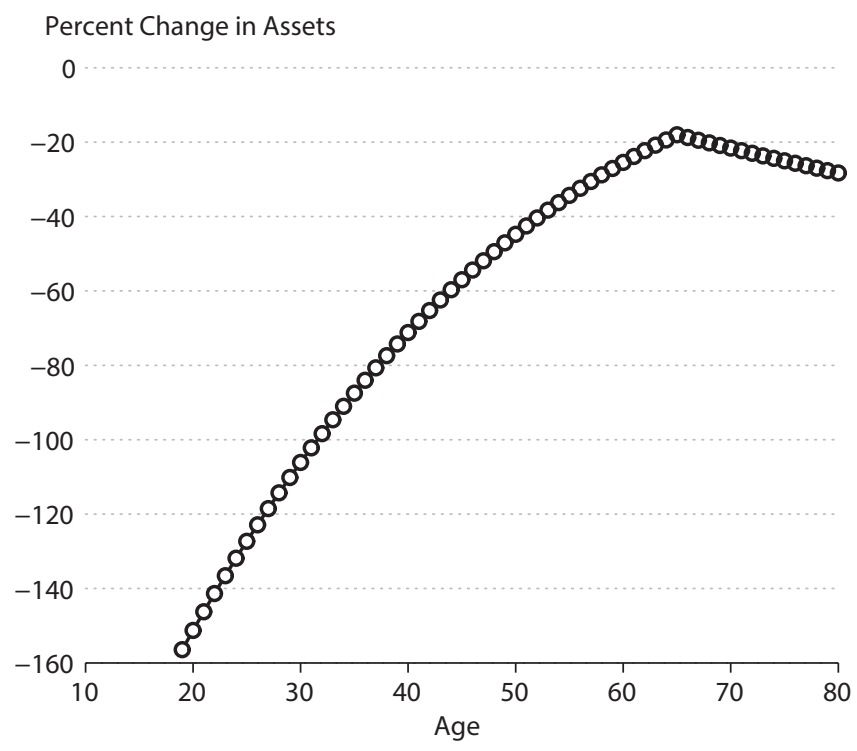

NOTE: From one balanced growth path to the next, individuals close to retirement age reduce their holdings relatively less than others.

contributes to more inequality. On the other hand, the change in the age composition of the population reduces inequality because it reduces the proportion of individuals with the least asset holdings: the young. When comparing the $n_{\text {bench }}$ economy with the $n_{1}$ economy, this latter effect dominates.

Now contemplate a further reduction in $n$, from $n_{1}$ to $n_{2}$. Why does inequality increase? Table 3 reveals that, in contrast to the previous difference between $n_{\text {bench }}$ and $n_{1}$, the dominating effect here is the economic effect. To be precise, the economic effect increases the Gini coefficient by 73 percentage points, while the demographic effect lowers it by 47 percentage points. 


\section{Figure 7}

\section{Effects of a Change in Life Expectancy}
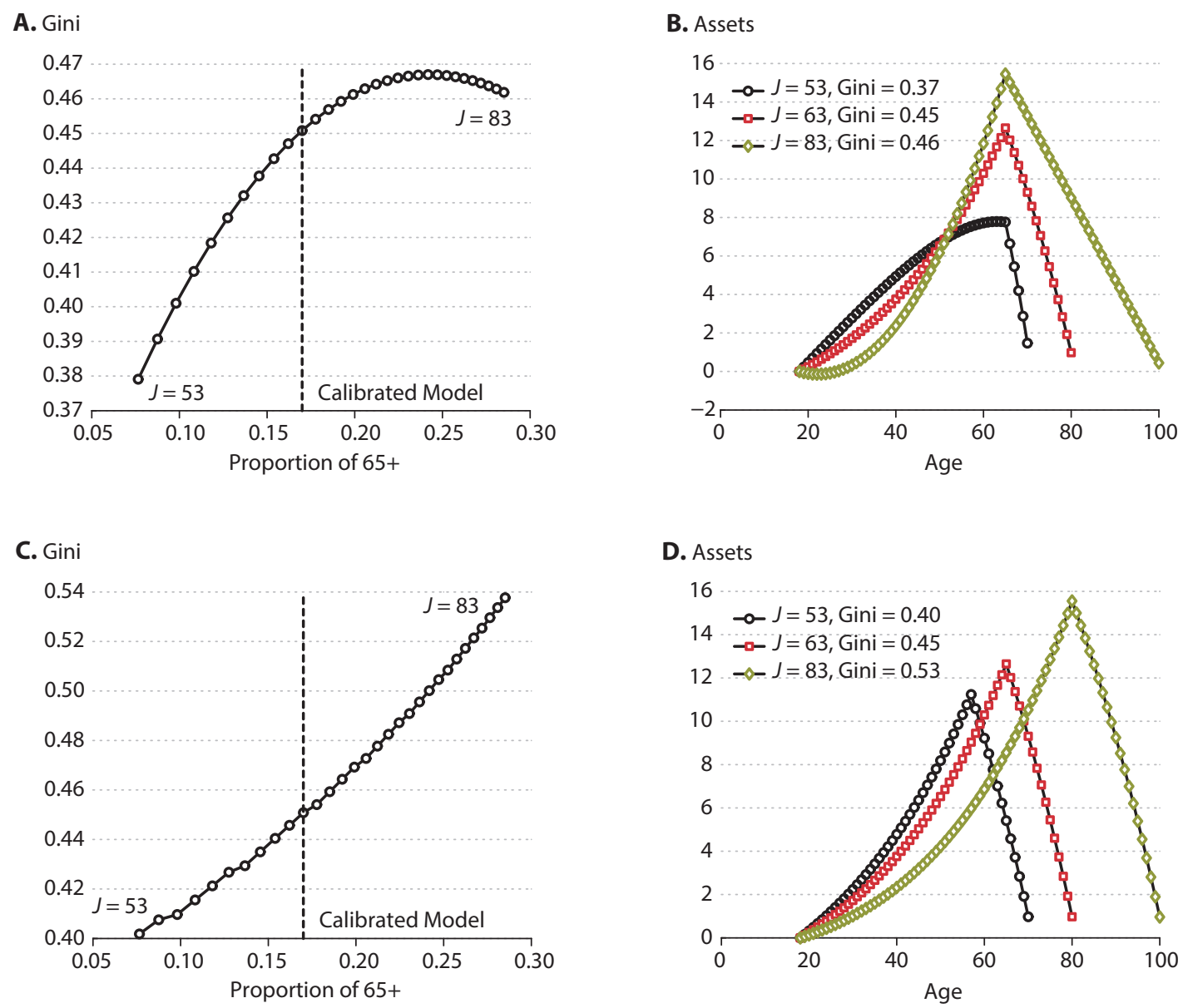

NOTE: Panels $A$ and $B$ report the results of an experiment where life expectancy, $J$, changes while the age of retirement, $R$, remains constant at the calibrated value, $R=48$. All other parameters are also held constant at their calibrated values. Panels $C$ and $D$ report the results of an experiment where $J$ and $R$ change in the same proportion so that the fraction of life spent in retirement remains the same at the value implied in the calibrated economy, 24 percent. All other parameters are held constant at their calibrated values.

3.2.2 The Effect of Life Expectancy. I consider different values for life expectancy, J, holding the population growth rate constant. I use values ranging from 53 to 83 -that is, from 10 years below the calibrated economy to 20 years above. As in the previous exercise, I compute a balanced growth path for each value of $J$.

For this exercise I distinguish two cases. First, I keep the age of retirement constant at its calibrated value, $R=45$, as $J$ changes. This implies that the fraction of one's life spent in retirement changes as $J$ changes. When $J=53$, for instance, one spends 9 percent $(1-48 / 53=0.09)$ of one's life in retirement. When $J=63$, as in the calibrated economy, this fraction is 24 percent. When $J=83$, this fraction is 42 percent. Panels A and B of Figure 7 report these results. 


\section{Table 4}

Decomposition of the Change in the Gini Coefficient with Life Expectancy Changes

\begin{tabular}{lccccccc} 
& \multicolumn{3}{c}{$R$ constant } & & \multicolumn{3}{c}{$R$ varying } \\
\cline { 2 - 3 } & $J=53$ & $J=J_{\text {bench }}$ & $J=83$ & & $J=53$ & $J=J_{\text {bench }}$ & $J=83$ \\
\hline Gini & 0.37 & 0.45 & 0.46 & & 0.40 & 0.45 & 0.53 \\
Total effect & & +0.08 & +0.01 & & +0.05 & +0.09 \\
Effect of $a$ & & +0.22 & +0.22 & & +0.20 & +0.29 \\
Effect of $\pi$ & -0.15 & -0.21 & & -0.15 & -0.20 \\
\hline
\end{tabular}

In a second experiment I consider values of $R$ that change as $J$ changes, such that the fraction of life spent in retirement remains constant at the value implied in the calibrated economy, 24 percent. Panels $\mathrm{C}$ and $\mathrm{D}$ of Figure 7 report these results. It is worth noting that the age composition of the population is the same regardless of whether $R$ is held constant. It is uniquely determined by $n$, which remains at its calibrated value, and by $J$.

The message from Figure 7 is that wealth inequality increases as a population grows older because its life expectancy increases. Decomposing the change in the Gini coefficient between the economic effect and the demographic effect, as in the previous exercise, reveals that the economic effect tends to increase wealth inequality, while the demographic effect tends to reduce it (Table 4). This is true regardless of whether the retirement age is held constant. Remember that the economic effect is the effect on the Gini coefficient of a change in the asset profile by age, holding the age composition constant. It increases inequality because $R$-old individuals accumulate more wealth when they expect to live longer. Since $R$ is the age at which asset holdings are at their maximum in the first place, an increase in life expectancy results in a concentration of wealth among the richest and thus yields a higher Gini coefficient. The demographic effect measures the effect on the Gini coefficient of a change in the age composition of the population, holding the asset profile by age constant. Since older people tend to be less numerous and tend to hold more wealth than younger people, an increase in the proportion of older people tends to reduce the Gini coefficient. Table 4 shows that the demographic effect tends to be small relative to the economic effect when life expectancy increases.

The results in Figure 7 contrast with those in Figure 5. To see this more precisely, consider an increase in the proportion of individuals age 65 and older from 17 percent (the calibrated economy) to 25 percent. Panel A of Figure 5 shows that if this increase results from a reduction in the population growth rate, the result is a decrease in wealthy inequality: The Gini coefficient decreases from 0.45 to about 0.32 . Panels $\mathrm{A}$ and $\mathrm{C}$ of Figure 7 show that if this increase in the proportion of individuals age 65 and older results from an increase in life expectancy, inequality increases: The Gini coefficient rises from 0.45 to almost 0.47 (Panel A of Figure 7) or more than 0.5 (Panel B of Figure 7).

Two points are worth mentioning at this stage. First, one reason for the different results (as emphasized above) between the two experiments stems from a stronger economic effect in the increased life expectancy experiment than in the lower population growth experiment. 
Why is that? The main difference is that when life expectancy increases, young individuals reduce their asset holdings so they can hold more when they reach retirement (see Panels B and $\mathrm{D}$ of Figure 7). In contrast, when the population growth rate decreases, individuals of all ages reduce their asset holdings (see Panel $\mathrm{C}$ of Figure 5). These differences in asset profiles explain the stronger concentration of wealth after an increase in life expectancy.

Second, the different results between the two experiments emphasized above do not hold everywhere. Panel A of Figure 5 shows that there are economies in which inequality can increase as the economy's population becomes older following a change in $n$. Similarly, Panel A of Figure 7 shows that there are economies in which inequality decreases as the age of the population increases following a change in $J$. Thus, the takeaway lesson from these numerical examples is of a qualitative nature: Assessing the effect of aging on wealth inequality depends critically on the cause of aging.

3.2.3 Optimal Retirement Age. As the previous discussion suggests, the retirement age is an important determinant of the wealth distribution since it is at this age that wealth concentrates. In this section, I consider a version of the model in which the retirement age is optimally chosen. The key questions are these: Does the age of retirement change significantly as the population becomes older? And if yes, then how does this change affect wealth inequality?

Here I modify the model presented earlier (see Section 2) slightly to endogenize retirement. Specifically, I let preferences be represented by

$$
\sum_{j=1}^{J} \beta^{j-1} \frac{\left(c_{t+j-1}^{j}\right)^{1-\sigma}}{1-\sigma}+\alpha \ln (J-R), \sigma, \alpha>0 .
$$

The novelty in this formulation is the introduction of a taste for the time spent in retirement: $\alpha \ln (J-R)$. When $\alpha=0$, which corresponds to the original model, an individual would not retire if given the choice since working causes no disutility and retirement entails a loss of income. When $\alpha>0$, however, the individual needs to choose his retirement age to balance the cost associated with the loss of income against the utility benefit of a longer retirement.

I calibrate the balanced growth path of this alternative model in the same way described in Section 3.1 with the addition that $\alpha$ must be given a value. I choose $\alpha$ so that the optimal retirement age is $R=48$, as in the calibrated model. This implies $\alpha=3.5$. All other parameters remain the same as before.

In this alternative model, a change in $n$, the population growth rate, has very little effect on the results discussed previously since the retirement age changes little. ${ }^{2}$ Changes in life expectancy have more noticeable effects on the retirement age. When $J=53$, the optimal retirement age is $R=41$, while when $J=83$, it is $R=62$. This implies that the fraction of life spent in retirement varies from 22 percent (when $J=53$ ) to 25 percent (when $J=83$ ). Thus, the results of this experiment with endogenous retirement are very similar to the results in Panels $\mathrm{C}$ and D of Figure 7, where the fraction of life spent in retirement was kept constant at 24 percent. 


\section{CONCLUSION}

In this article, I use a simple version of the optimal growth model to assess the effect of demographic changes on wealth inequality. Two forces affect inequality when a population becomes older: First, a demographic effect tends to reduce inequality. As the population grows older, there are relatively fewer young individuals who typically own less wealth. This tends to reduce the Gini coefficient of wealth. A second effect, the economic effect, acts in the opposite direction. As the share of the older population increases, wealth tends to concentrate among those close to retirement. This tends to increase the Gini coefficient on wealth.

I conducted two experiments using a version of the model calibrated to the U.S. economy. When aging increases relative to current U.S. demography, wealth inequality may decrease or increase depending on the causes of aging. When life expectancy increases, the economic effect dominates and inequality tends to increase. In contrast, when the population growth rate decreases, the demographic effect dominates and inequality tends to decrease.

The model used here is a simple version of the optimal growth model. An interesting extension is to augment it with a realistic description of progressive taxation and a social security scheme. I leave this for future research. 


\section{APPENDIX: THE STATIONARY ECONOMY}

\section{Demography}

Equation (1) implies $p_{t}^{1}=n^{j-1} p_{t-j+1}^{1}$, and equation (2) implies $p_{t}^{j}=p_{t-j+1}^{1}$. It follows that the total population, $P_{t}$, is proportional to the age- 1 population:

$$
\frac{P_{t}}{p_{t}^{1}}=\sum_{j=1}^{J} \frac{p_{t}^{j}}{p_{t}^{1}}=\sum_{j=1}^{J} \frac{p_{t-j+1}^{1}}{n^{j-1} p_{t-j+1}^{1}}=\sum_{j=1}^{J} \frac{1}{n^{j-1}} .
$$

Hence, population grows at the (gross) rate $n: P_{t+1} / P_{t}=n$. Define $x(n, J) \equiv \sum_{j=1}^{J} 1 / n^{j-1}$. The share of age- $j$ individuals in the total population, $\pi^{j}=p_{t}^{j} / P_{t}$, is constant over time and given by

$$
\pi^{j}=\frac{1}{n^{j-1} x(n, J)}
$$

Technology and Profit Maximization. The output-to-capital ratio is constant along the balanced growth path-that is, $Y_{t} / K_{t}=\left(z_{t} N_{t} / K_{t}\right)^{1-\theta}$ is constant. This implies that $K_{t}$ grows at the same rate as the efficiency units of labor employed, $z_{t} N_{t}$. In equilibrium, labor demand grows at the population growth rate, $n$. It follows that aggregate output and the aggregate stock of capital grow at rate $g n$ along the balanced growth path. Prices are given by marginal products; therefore,

$$
\begin{aligned}
w_{t} & =(1-\theta) z_{t}\left(\frac{K_{t}}{z_{t} N_{t}}\right)^{\theta}, \\
r_{t}+\delta & =\theta\left(\frac{K_{t}}{z_{t} N_{t}}\right)^{\theta-1} .
\end{aligned}
$$

Thus, the interest rate, $r$, is constant and the wage rate, $w_{t}$, grows at rate $g$. Define $\hat{w}=$ $w_{t} / z_{t}, k=K_{t} /\left(z_{t} N_{t}\right)$, and $y=Y_{t} /\left(z_{t} N_{t}\right)=k^{\theta}$. Then,

$$
\begin{aligned}
\hat{w} & =(1-\theta) k^{\theta}, \\
r+\delta & =\theta k^{\theta-1} .
\end{aligned}
$$

Note that the objective of the firm, expressed in transformed variables, is to maximize profit per efficiency units of labor:

$$
\max _{k} k^{\theta}-(r+\delta) k-\hat{w}
$$

Also note that the first-order conditions associated with this problem are the same as the one just derived.

Preferences and Individual Optimization. Since individual variables grow at rate $g$, define $\hat{c}^{j} \equiv c_{t}^{j} / z_{t}$ and $\hat{a}^{j} \equiv a_{t}^{j} / z_{t}$. The utility function then reads 


$$
\begin{aligned}
\sum_{j=1}^{J} \beta^{j-1} \frac{\left(c_{t+j-1}^{j}\right)^{1-\sigma}}{1-\sigma} & =\sum_{j=1}^{J} \beta^{j-1} \frac{\left(\hat{c}^{j} z_{t+j-1}\right)^{1-\sigma}}{1-\sigma} \\
& =\sum_{j=1}^{J} \beta^{j-1} \frac{\left(\hat{c}^{j} g^{j-1} z_{t}\right)^{1-\sigma}}{1-\sigma},
\end{aligned}
$$

which is equivalent to preferences represented by $\sum_{j=1}^{J} \tilde{\beta}^{j-1} \frac{\left(\hat{c}^{j}\right)^{1-\sigma}}{1-\sigma}$, where $\tilde{\beta} \equiv \beta g^{1-\sigma}$. Dividing the period budget constraint (equation (6)) by $z_{t+j-1}$ yields

$$
\hat{c}^{j}+g \hat{a}^{j+1}=\hat{w} \mathbb{I}(j<R)+(1+r) \hat{a}^{j} .
$$

Thus, the transformed individual's optimization problem is

$$
\begin{array}{ll}
\max & \sum_{j=1}^{J} \tilde{\beta}^{j-1} \frac{\left(\hat{c}^{j}\right)^{1-\sigma}}{1-\sigma} \\
\text { s.t. } & \hat{c}^{j}+g \hat{a}^{j+1}=\hat{w} \mathbb{I}(j<R)+(1+r) \hat{a}^{j} .
\end{array}
$$

The first-order conditions associated with this problem imply the following Euler equation:

$$
\left(c^{j}\right)^{-\sigma}=\frac{\tilde{\beta}}{g}(1+r)\left(c^{j+1}\right)^{-\sigma},
$$

which equates the marginal cost of saving at age $j$ (left-hand side) to its marginal benefit (righthand side).

\section{Equilibrium}

Dividing the market clearing condition for savings (equation (9)) by $z_{t} N_{t}$ yields

$$
k=\sum_{j=1}^{J} \frac{\pi^{j}}{\sum_{j=1}^{R-1} \pi^{j}} \hat{a}^{j} .
$$

Dividing the market clearing condition for goods (equation (9)) by $z_{t} N_{t}$ yields

$$
\sum_{j=1}^{J} \frac{\pi^{j}}{\sum_{j=1}^{R-1} \pi^{j}} \hat{c}^{j}+g n k=y+(1-\delta) k
$$




\section{Vandenbroucke}

\section{NOTES}

1 Since there are more older individuals, the fact that individuals save less at each age is not inconsistent with the fact that there is more capital in the economy.

2 Details are available upon request.

\section{REFERENCES}

Chatterjee, Satyajit. "Transitional Dynamics and the Distribution of Wealth in a Neoclassical Growth Model." Journal of Public Economics, May 1994, 54(1), pp. 97-119.

Cooley, Thomas F. and Prescott, Edward C. "Economic Growth and Business Cycles," in Thomas F. Cooley, eds., Frontiers of Business Cycle Research. Chap. 1. Princeton, NJ: Princeton University Press, 1995, pp. 1-38.

Díaz-Giménez, Javier; Glover, Andy and Ríos-Rull, José-Víctor. "Facts on the Distributions of Earnings, Income, and Wealth in the United States: 2007 Update." Federal Reserve Bank of Minneapolis Quarterly Review, February 2011, 34(1), pp. 2-31.

Greenwood, Jeremy and Seshadri, Ananth. "The U.S. Demographic Transition." American Economic Review, May 2002, 92(2), pp. 153-59.

Greenwood, Jeremy and Vandenbroucke, Guillaume. "Hours Worked (Long-Run Trends)," in Lawrence E. Blume and Steven N. Durlauf, eds., The New Palgrave Dictionary of Economics. Second Edition. London: Palgrave Macmillan, 2008, pp. 75-81; doi:10.1057/9780230226203.0748.

Lucas, Robert E. "Econometric Policy Evaluation: A Critique." Carnegie-Rochester Conference Series on Public Policy, 1976, 1(1), pp. 19-46.

McGrattan, Ellen R. and Prescott, Edward C. "Is the Stock Market Overvalued?" NBER Working Paper No. 8077, National Bureau of Economic Research, January 2001; http://www.nber.org/papers/w8077.pdf. 